\title{
' The Analysis of Techniques for Learning a Foreign Language through Translation
}

\author{
Yeyu Chen \\ Minnan Science and Technology Institute \\ Fujian Normal University \\ Nanan, Fujian, 362332, China
}

\begin{abstract}
Translation method has been a controversial issue in foreign language teaching field. From the perspective of unique social, cultural and historical background in China, translation method has its applicability and values in foreign language learning. Translation method has some own advantages and limitations as well. In this article, we propose some techniques for learning foreign language through translation method, so that learners can better improve their language skills.
\end{abstract}

Keywords- Translation Method; Foreign Language; Learning Techniques

\section{INTRODUCTION}

Therehasbeenalongtraditionofusingtranslationasameansfo rlearningasecondofforeignlanguage.Untiltheendoftheeighteen thcentury,aforeign language meant Latin and Greek, and the learning of them was based on bi-lingual word list sand parallel texts. When modern languages be gan to be taught at the end of the century, the same approach was adopted, and it be came known as the grammar-translation method, since learnerswerepresentedwithrulesandthenappliedthemintranslat ion.

However, translation method is generally a "pretheoretical" approach, i.e. it developed before the ageoftheoretical constructionsinlinguistics, psychologyand pedagogywhichhave

providedtheoreticalbasisforlaterapproachessuchasthe communicativeapproach.Atkinson(1978)hasasserted,"Thega pinmethodologicalliterature is presumably partiallyresponsiblefortheuneasinesswhichmanyteachersfeela boutusingor learners,nativelanguage."Thelackof

positiveliteratureavailableonusingtranslationinthe classroom, andthenegative

commentsitreceivesbythelinguistsandtrainer,have

certainlymadeteachersbecautiousofexperimentingwithitordoi ngresearchonit.

Generally speaking, through continuous adjustments and improvements, translation method is entirely possible to get the innovative use in foreign language learning in our country.

\section{FEATURES OF TRANSLATION Method}

Grammar-translation method first appeared at the end of the eighteenth century, and it is closely associated with limitations of people's understanding of language and specific historical background at that time.Grammartranslation method held that the purpose of language learning is to read literary classics or promote cultural knowledge training. In learning, translation method generally adopts such a way: first carefully analyzes the syntax rules, and then apply grammar knowledge learned in translation exercises. Learners need to translate the sentences from mother tongue to foreign language or the opposite. In this way, it requires the learners have a high level of translation skills.

Compare with other learning method, the advantages and limitations of translation method are as follow:

(1) Advantages

1) Translation method emphasizes on grammar learning. In recent years, many studies have proved grammar comprehension is very helpful for foreign language learning. Systematic grammar learning would deepen learners' comprehension of the target language, and grasp of overall structure of the language.

2) Translation method focuses on reading. In general, by reading literary of target language to learn foreign language, not only cultivate the reading skill, but also conducive to the learners a deeper understanding of the target language.

3) Translation method contrasts the mother tongue and the target language, to reveal the similarities and differences between the two languages, so that learners can better understand it.

4) In practical learning, translation method has strong operability and simplicity, and meanwhile, it is easier to carry on the teaching test.

(2) Limitations

1) Translation method generally ignores learners' oral and listening abilities, so unable to achieve the purpose of communicative competence of learners.

2) Mutual-translation means will make learners rely too much on mother tongue, and be accustomed to word for word and sentence for sentence translation habits.

3) Translation method devilishly emphasis on grammar knowledge, but neglect the training of language skills.

4) Materials and texts of translation method are generally originated from literary works, which are difficult to understand and away from the actual use of language. 
5) The teaching process of translation method often relies too much on the teachers, while learners participate less in learning. Meanwhile, the learning form is single, with mechanical memorizing grammar rules as the main content, hard to lift the enthusiasm of learners.

\section{VALUES OF TRANSLATION METHOD}

\section{(1) For LearningSubjects}

Learning subject refers to the foreign language learners. Under the current situation of foreign language teaching status in China, because ofSubject to environmental constraints, learners are always just "learning" language, but not "acquiring" it. Higher education transforms form elite education to mass education, leading to students quality drop. Taking oral proficiency for example, many learners are weak in using appropriate language to exchange profound ideas. The cultural ideological education accepted from children makes them behave introverted and implicit in language. They rely too much on teachers in learning, and tend to regard teachers as authorities. Translation method is emphasizing the role of teachers, and pays attention to cultivation of learners' basic language skills.

(2) For Learning Object

Learning object refers to the target language. Because of the unique language environment in China, it is suitable to learn foreign language through translation method. First, due to differences in the region and the environment, learners' foundation is uneven.Purpose of foreign language learning is coherent but its curriculum is not. Foreign language learning is completed in stages, and may terminate the in school learning. Herein, learners should take continued learning in the first place. Yet the best way to continue learning is translation method, because translation method is systematically scientific and practical. Second, Chinese and most foreign language are belonging to different language systems, and many learners start to learn foreign language after firm foundation of mother tongue. From the perspective of psychology, most learners unconsciously contrast the foreign language and their mother tongue. So for the foreign language beginners, it is necessary to help learn foreign language through mother tongue; even for high-level learners, sometimes translation is also helpful for them to better understand it.

(3) For Learning Environment

The language learning environment in China is mainly non-native-speaking environment, totally different from native-speaking environment. Spolysky thought that, environment can affect language learning in two aspects: one is learners' attitude; another is social policy and learning opportunity.From this perspective, the value of translation method in current foreign language learning environment lies in:

1) Teachers'knowledge level and teaching level is still to be improved. Foreign language learning is closely associated with teachers. However, quality foreign language teachers in China are uneven, so it is hard to create a near real communicative situation for the learners merely by teachers. Therefore, from the point of view of present teaching conditions, it is quite a realistic choice to adopt translation method to organize language learning.

2) The reality of lack of target language environment will maintain for a long term. Currently, most of the learners mainly study foreign language in the classroom, without corresponding practice places, so it is difficult for them to master the regularity of language through the influence of the language environment. So we should better adoptcognitive translation method, by teachers' detailed explanation, to guide learners infer other things from one fact, so that firmly grasp the language.

\section{TECHNIQUES OF TRANSLATION METHOD IN FOREIGN LANGUAGE LEARNING}

Since translation method has its rationality and value in foreign language learning, then in the actual learning process, how do we employ the techniques of it to better improve our comprehensive skills of foreign language?

(1) First, improve grammar learning methods and means. We should recognizing the necessity of grammar in foreign language learning, and change the grammar learning concepts. Grammar learning is not the purpose, but the means. The ultimate goal of grammar learning lies in applying grammar rules in language exchange. Therefore, learners should get rid of the concept of learning grammar just for grammar. In addition, should be in line with a gradual approach and employ more learning means as much as possible. For example, through the situations that close to real life, learners find out when, how, and why to use the grammar rules.

(2) Second, in aspects of intonation, oral and listening skill, reference the advantages of other methods like communicative method, audio-visual method, situation method, etc. Translation method has put up a solid framework for learners, to ensure their correctness in language expression and communicate, which is the foundation of language learning. However, besides the correctness, fluency of language expression is also a key indicator. So it requires translation method absorbed the strengths of other learning methods.

(3) Third, improve the mutual-translation means and mother tongue learning media. On the one hand, mutualtranslation means reveals thesimilarities and differences between mother tongue and foreign language. Learners should focus on thesocial and cultural knowledge of the target language, and further understand the creation and development background of these two languages. On the other hand, in foreign language learning process through mother tongue media, learners should recognize that it is a dialectical relationship between mother tongue and the foreign language. In the beginner stage, the appropriate use of mother tongue would help learners understand the target language; however, with the rich of foreign language knowledge and raise of foreign language skills, learners should gradually reduce the dependence on the mother tongue. That is to say, to what extent translation method should bu used in foreign language learning depends on learning environment and skill level of learners 


\section{CONCLUSION}

China's unique foreign language learning environment and teaching realities determine the grammar-translation method is still playing a key role in our country's foreign language learning. Meanwhile, as a long-history and tenacious-vitality language learning methods, translation method itself is constantly developing, in aspect of teaching concept, teaching purpose, teaching mode, etc.

\section{REFERENCES}

[1] Atkinson D. The mother tongue in the classroom: A neglected resource?[J]. ELT journal, 1987, 41(4): 241-247.

[2] August D, Carlo M, Dressler C, et al. The critical role of vocabulary development for English language learners[J]. Learning Disabilities Research \& Practice, 2005, 20(1): 50-57.

[3] Kern R G. The role of mental translation in second language reading[J]. Studies in second language acquisition, 1994, 16(04): 441461.
[4] Dong T, Cremers A B. A Novel Machine Translation Method for Learning Chinese as a Foreign Language[M]//Computational Linguistics and Intelligent Text Processing. Springer Berlin Heidelberg, 2014: 343-354.

[5] Chang S C. A contrastive study of grammar translation method and communicative approach in teaching English grammar[J]. English Language Teaching, 2011, 4(2): p13.

[6] Grover P. Teaching of English in Indian Schools through Grammar Translation Method-Low Performance-A Field Study[J]. Open Access Library Journal, 2014, 1(5).

[7] Catena Fontalba M, Stephens S. Out with the new in with the old: revisiting the Grammar Translation Method in foreign language teaching[J]. 2012. 